\title{
Comportamiento de la proteína de forraje verde hidropónico en función del tiempo de cosecha
}

\section{Behavior of the forage protein versus time hydroponic crop}

\author{
Moyano Hernández Luis Francisco ${ }^{1}$ y Sánchez Moreno Hugo Vladimir ${ }^{2}$ \\ ${ }^{1}$ Medico Veterinarios Zootecnista, \\ ${ }^{2}$ MVZ., Esp., MSc. Docente Universidad de los Llanos
}

\section{moyano108@gmail.com}

Recibido 21 de Junio 2012, Aprobado 25 de Septiembre 2012

\section{RESUMEN}

El forraje verde hidropónico (FVH) es una de las variantes de la hidroponía; proceso que consiste en la germinación rápida de semillas viables de algunos cereales realizada en instalaciones adecuadas para tal fin y bajo procesos controlados, por un lapso de tiempo no mayor a los 12 días; 9 de los cuales se suministra a las plántulas soluciones nutritivas, lo que produce al final del ciclo un tapete compuesto por granos germinados, con sus raíces, tallos y hojas verdes; la biomasa vegetal así obtenida es de alta sanidad y calidad nutricional. Constituye pues una muy interesante posibilidad para suplir eficientemente las dietas de animales rumiantes y no rumiantes. Se pretende socializar, los datos, experiencias y resultados obtenidos sobre FVH producido en Colombia, con el ánimo de que este se constituya en una herramienta útil a los interesados en la implementación de esta tecnología. Para desarrollar los objetivos del proyecto, se obtuvo material vegetativo a los 4, 6, 8, 10, 12 y 14 días de cosecha, del cual se tomó una muestra al azar y se realizó análisis bromatológico en el laboratorio de nutrición animal de la Universidad de los Llanos, el cual pretendió establecer el comportamiento de la proteína de FVH en función del tiempo de cosecha. El FVH de Zea maíz presenta su pico máximo de contenido proteico en el día decimo a partir del cual empieza a descender levemente hasta el día doce y de allí en adelante presenta un descenso vertiginoso. El tiempo máximo de germinación de las plántulas no debe exceder el día doce.

Palabras clave: Forraje verde hidropónico, hidroponía, germinación, proteína, análisis bromatológico. 


\begin{abstract}
The hydroponic green fodder (HGF) is a variant of hydroponics; process of rapid germination of viable seeds of some cereals held in adequate facilities for that purpose and under controlled processes, for a period of time no longer than 12 days, 9 of which is supplied to seedlings nutrient solutions, which occurs at the end of the cycle consists of a mat sprouted grains, with their roots, stems and green leaves plant biomass thus obtained is of high health and nutritional quality. Is thus an interesting possibility to supply efficiently diets of ruminants and non-ruminants. It aims to socialize, data, experiences and results obtained on HGF produced in Colombia, with the hope that this would constitute a useful tool for those interested in implementing this technology. To develop the project objectives, vegetative material was obtained at 4, 6, 8, 10, 12 and 14 days of harvest, which will take a random sample and chemical composition analysis was conducted in the laboratory of animal nutrition at the University of the Plains, which sought to establish the behavior of HGF protein versus time of harvest. The HGF of Zea maize shows a peak of protein on the tenth day after which begins to decline slightly to twelve days thereafter presents a precipitous decline. The maximum germination of seedlings the day should not exceed twelve.
\end{abstract}

Keywords: Hydroponic green fodder, hydroponics, germinating, protein, compositional analysis.

\title{
INTRODUCCIÓN
}

Una de las mayores preocupaciones que actualmente enfrenta la producción pecuaria mundial es la manera de contrarrestar los fenómenos climáticos desencadenados por el calentamiento global. Los hechos, estadísticas y pronósticos que poseemos al respecto, no pueden menos que alertarnos, pero al mismo tiempo son sin duda alguna, una voz de alarma que nos previene sobre la imperiosa necesidad de implementar sistemas eficientes de producción encaminados a enfrentar dichas eventualidades que sacudirán al planeta en el futuro inmediato. Estos mismos vaticinios son los que nos obligan como academia a buscar y proponer alternativas nutricionales que permitan 
evitar o prevenir perdidas productivas de origen alimentario, cualquiera que sea su origen (Hidalgo et al., 2001).

La producción de suplemento alimenticio tipo forraje verde hidropónico (FVH) es una de las variantes de la hidroponía; el proceso consiste básicamente en la germinación rápida de semillas viables de algunos cereales o leguminosas realizada en instalaciones adecuadas para tal fin y bajo procesos controlados, por un lapso de tiempo no mayor a los 12 días; 9 de los cuales se suministra a las plántulas soluciones nutritivas, lo que produce al final del ciclo un "tapete", compuesto por granos germinados, sus raíces entrelazadas, tallos y hojas verdes que pueden tener para esa época una altura de hasta $35 \mathrm{~cm}$ aproximadamente; la biomasa vegetal así obtenida es de alta sanidad y calidad nutricional. Debido a este método de producción, el FVH puede elaborarse en cualquier época y en cualquier localidad geográfica, siempre y cuando se establezcan las condiciones mínimas necesarias para ello. Es de anotar que debido al rápido crecimiento de la semilla durante este proceso germinativo se activan enzimas que movilizan las reservas de almidón y proteínas de la semilla, transformándolas en principios nutritivos básicos (aminoácidos y azucares) creando nuevos tejidos vegetales ricos en vitaminas totalmente asimilables y favorables para el metabolismo animal. De esta forma se obtiene un alimento natural altamente digestible que incrementa los rendimientos productivos y mejora los niveles sanitarios de los animales. "El FVH es un alimento (forraje vivo en pleno crecimiento) verde, de alta palatabilidad para cualquier animal y excelente valor nutritivo (Chen, 1975; Less, 1983; Níguez, 1988; Santos, 1987; y Dosal, 1987)" (Ibid).

El sistema de producción de forraje verde hidropónico $(\mathrm{FVH})$ ha posibilitado entre otras, obtener mayor calidad de carne, aumento del peso vivo a la fecha de faena, aumento en la proporción de pelo de primera en el vellón de conejos, mayores volúmenes de leche, aumento de la fertilidad, disminución de los costos de producción por sustitución parcial de la ración por FVH (Ibid). En este sentido el FVH constituye una muy interesante posibilidad para suplir eficientemente las raciones o dietas de animales rumiantes y no rumiantes. No obstante, y a sabiendas de que la hidroponía no es una tecnología reciente a nivel mundial y que en nuestro medio ha sido poco investigada y tratada, se 
justifica pues, el tratar de incursionar en el aprendizaje de esta tecnología, con el objetivo de ver su aplicación, posibilidad y futuro en nuestro entorno. Realizando una primera aproximación al tema tratando de establecer el comportamiento de la proteína de FVH en función del tiempo de cosecha.

Los usos del FVH son diversos pudiéndose utilizar como alimento de bovinos, equinos, porcinos, caprinos, ovinos, aves entre otros. Las dosis en que puede ser usado el FVH en diversas especies de animales, dependen de factores como peso vivo del animal, raza, y estado fisiológico o reproductivo. Siendo necesaria aún mayor investigación para ajustar los consumos diarios. Teniendo siempre en cuenta la condición del FVH como excelente suplemento y no como un reemplazo total de la dieta, en este orden de ideas la recomendación general para estos casos es tratar que el FVH no supere el $50 \%$ de la dieta diaria del animal para el caso de los rumiantes y su dosificación sea siempre monitoreada y analizada por un profesional capacitado.

El FVH contiene todas las enzimas y aminoácidos necesarios para la alimentación animal, pero dadas las características de los rumiantes se debe completar la alimentación con un aporte de fibra la cual se consigue en la paja seca, esto es solo para mantener el rumen del animal y el volumen de sus estómagos, la paja aportada puede no tener valor alimenticio, puede ser de descarte de cosecha o comúnmente llamado de rastrojo, sin ningún valor alimenticio.

La composición de los alimentos debe ser la base sobre la cual se deciden los ingredientes que deben usarse y sus combinaciones. La información composicional puede obtenerse en dos formas: a partir de valores tabulados o por el análisis químico de los alimentos. Los primeros son útiles para tener una idea general sobre la composición del alimento, pero su desventaja es que se elaboran a partir de promedios, por lo que no puede determinarse si el ingrediente con el que se cuenta esta dentro de ese promedio o fuera de él. Además, el empleo de este sistema excluye la posibilidad de la detección temprana de ingredientes adulterados con productos de apariencia similar. Los datos que se obtienen a partir de análisis químicos, si bien son más exactos, para ser representativos dependen de que la muestra analizada se haya 
tomado bien, o sea que un muestreo deficiente de un ingrediente puede dar información fuera de la realidad, como en el caso de los valores tabulados. Una desventaja adicional de los métodos analíticos es su costo y el tiempo que se toman (Shimada, 2003).

Desde el punto de vista nutricional el FVH posee un muy aceptable contenido de proteína, Vitamina E, complejo B. y se sospecha que, a la vez, el FVH es generador de las vitaminas esenciales como la Vitamina A y la Vitamina C (Hidalgo et al., 2001).

Tabla 1. Análisis bromatológico de FVH de maíz

\begin{tabular}{|l|c|c|}
\hline \multicolumn{1}{|c|}{ DETERMINACIÓN } & $\begin{array}{c}\text { BASE } \\
\text { HÚMEDA }\end{array}$ & $\begin{array}{c}\text { BASE } \\
\text { SECA }\end{array}$ \\
\hline HUMEDAD \% & 77,65 & -- \\
\hline CENIZAS \% & 0,41 & 1,84 \\
\hline PROTEÍNA \% & 2,74 & 12,26 \\
\hline EXTRACTO ETÉREO \% & 0,95 & 4,25 \\
\hline FIBRA CRUDA \% & 1,98 & 8,87 \\
\hline E.L.N. & 16,27 & 72,78 \\
\hline
\end{tabular}

Análisis efectuado por: Laboratorio de Análisis Industriales, I.B.Q. CORALIA MORA UZETA. Colón 156 ote. Tel 15-26-77 Culiacán, Sinaloa. Reg. SS. JI-0038 - REG. S.A.R.H. 00075.

\section{MATERIALES Y MÉTODOS}

Se recopilo información, obtenida en los procesos de construcción o implementación de tres plantas productoras de $\mathrm{FVH}$, que el autor ha instalado en distintas explotaciones a saber: Finca Golconda, ubicada en el municipio de puerto López Meta que pertenece a la unidad bioclimática de la megacuenca de sedimentación de la Orinoquia. En la definición de Caldas-Lang corresponde al clima cálido semi-húmedo. Considerando los promedios históricos de la precipitación en cinco estaciones ubicadas de manera equidistante dentro del municipio, podemos establecer que las lluvias aumentan del SE-E hacia el NW$\mathrm{N}$ con valores entre los 2.000 y $2.700 \mathrm{~mm}$ en promedio. Distribuidos en aproximadamente 120 días, donde los meses de Junio y Julio son los más lluviosos, y Enero y Febrero los más secos. el promedio de la temperatura está entre los 26 y $26.5^{\circ} \mathrm{C}$, siendo Febrero y Marzo los meses más cálidos con 
valores entre los 27 y $28^{\circ} \mathrm{C}$ y Junio y Julio los más fríos con valores promedios de $24^{\circ} \mathrm{C}$. Las temperaturas máximas absolutas han superado los $38.5^{\circ} \mathrm{C}$ y las mínimas absolutas han descendido hasta los $14^{\circ} \mathrm{C}$. Altitud 178 m.s.n.m. (metros sobre el nivel del mar). Granja Las Gemelas ubicada en el municipio de La Mesa Cundinamarca. El área municipal de La Mesa está distribuida en cerca de $148 \mathrm{~km}^{2}$, montañosos en la mayoría, donde no faltan las zonas onduladas, con una altitud: 1200 m.s.n.m. Temperatura media: $22^{\circ} \mathrm{C}$. Finca Villa Daniela, ubicada en el municipio de Girón Santander, que forma parte del área Metropolitana de Bucaramanga, tiene una temperatura promedio de $24^{\circ} \mathrm{C}$, una altitud de 777 m.s.n.m. y su topografía es montañosa.

Respecto a la semilla, solo se trabajó con semilla de Zea maíz, de distintas variedades de acuerdo a la disponibilidad de cada zona en la que fue montado el sistema. En cuanto a las soluciones nutritivas se emplearon soluciones nutritivas $A$ y $B$, comerciales del tipo hidroponía industrial, ya que su conveniencia y precio hacen viable su uso. Una vez obtenido el material vegetativo se eligieron muestras al azar, los días 4, 6, 8, 10, 12 y 14, las cuales fueron analizadas por el Laboratorio de Nutrición Animal de la Universidad de los Llanos, con lo cual, se estableció el comportamiento de la proteína de FVH en función del tiempo de cosecha.

Si vemos de una manera superficial a las proteínas, como sustancias formadoras de tejidos, que dan al animal la estructura de su conformación física: los músculos, los huesos, las vísceras, etc., aunque realmente en estos procesos intervengan algunas cantidades, otras sustancias como ácidos grasos, hidratos de carbono y minerales. Son las proteínas a las que se les presta más atención para evaluar el valor nutritivo de un alimento. En este sentido los resultados de los análisis bromatológicos del contenido de proteína a diferentes días de cosecha de F.V.H. de Zea maíz producido en la finca Golconda del municipio de Puerto López Meta, realizados por el Laboratorio de Nutrición Animal de la Universidad de los Llanos, se reflejan en el Gráfico 1. 


\section{RESULTADOS}

Los análisis bromatológicos realizados en el Laboratorio de nutrición animal de la Universidad De Los Llanos, al FVH de Zea maíz a los 12 días de cosecha, arrojaron los siguientes resultados presentados en la Tabla 2.

Tabla 2. Análisis bromatológico del forraje verde hidropónico (FVH) de Zea maíz de 12 días de germinación

\begin{tabular}{cc}
\hline Análisis & Contenido (\%) \\
\hline Humedad final & 5.39 \\
Cenizas & 2.86 \\
Extracto etéreo & 8.23 \\
Proteína cruda & 11.0 \\
Fibra cruda & 3.54 \\
ENN & 68.65 \\
NDT & 89.65 \\
EB & 4.08 \\
ED & 4.0 \\
EM & 3.24
\end{tabular}

Análisis realizado en el Laboratorio de Nutrición Animal de la Universidad de los Llanos

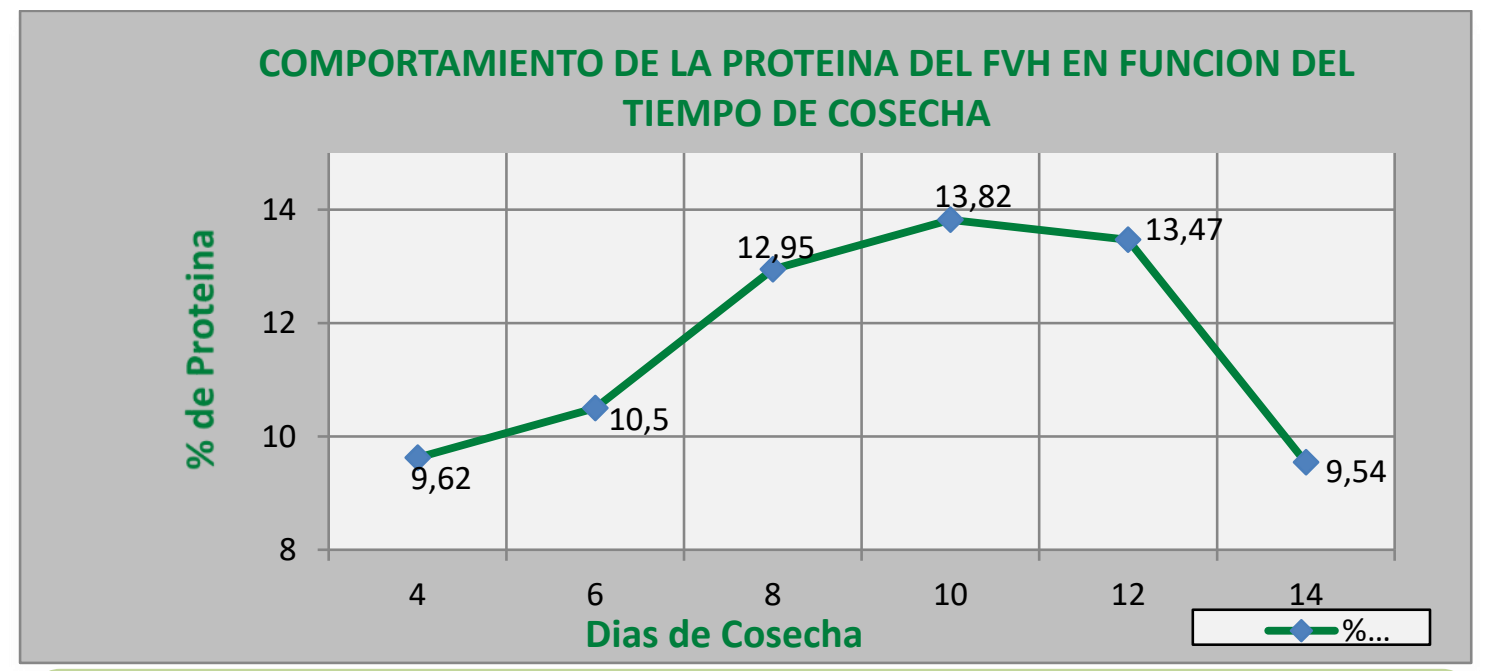

Gráfica1. Comportamiento de la proteína del FVH de Zea maiz en función del tiempo de cosecha. 


\section{DISCUSIÓN}

Como se puede observar, el comportamiento de la proteína del FVH de Zea maíz en función del tiempo de cosecha, de la muestra analizada presenta su pico máximo de contenido proteico en el día decimo a partir del cual empieza a descender levemente hasta el día doce y de allí en adelante presenta un descenso vertiginoso, lo cual es compatible con reportes publicados por expertos en la materia. Es por esta razón que se ha establecido como premisa fundamental del $\mathrm{FVH}$, que el tiempo máximo de germinación de las plántulas no debe exceder el día doce. La decisión de día diez, once, o doce dependerá entonces del área foliar alcanzada y peso del tapete pues en esta etapa el crecimiento está en plena expresión.

Entre los resultados más promisorios se ha demostrado la gran variedad de alternativas de uso del FVH así:

- Según: Less, 1983; Pérez, 1987; Bravo, 1988; Sánchez, 1997; Arano, 1998. Los conejos en engorde aceptaron hasta 180-300 g FVH/día (10$12 \%$ del peso vivo); ingesta de las madres en lactancia hasta $500 \mathrm{~g}$ $\mathrm{FVH/día.}$

- Aumento significativo de peso vivo en corderos precozmente destetados al suministrarles dosis crecientes de FVH hasta un máximo comprobado de 300 gramos de materia seca al día (Morales, 1987).

- Aumento de producción en aves domésticas (pollos, gallinas, patos, gansos, etc.) a partir del uso del FVH (Falen y Petersen, 1969 y Bull y Petersen,1969 citados por Bravo Ruiz,1988), lográndose sustituir entre un 30 a $40 \%$ de la dosis de ración peletizada pero asociado al riesgo, en casos de exceso en el uso de FVH, de un incremento de excreta de heces líquidas y fermentaciones aeróbicas del estiércol, malos olores de los locales, aumento de insectos voladores no deseados y aumento de enfermedades respiratorias especialmente en verano.

- Ganancia de peso en cerdos con una alimentación en base a FVH "ad libitum" (Sánchez, 1996 y 1997).

- Aumento de producción en vacas lecheras a partir del uso de FVH obtenido de semillas de avena variedad "Nehuén" y cebada cervecera 
variedad "Triumph" existiendo también en este caso antecedentes en el uso del maíz, sorgo, trigo, arroz y tritricale. (Sepúlveda, 1994).

- Sustitución en conejos, de hasta el $75 \%$ del concentrado por FVH de cebada sin afectar la eficiencia en la ganancia de peso alcanzándose el peso de faena (2,1 a 2,3 $\mathrm{kg}$ de peso vivo) a los 72 días. (Sánchez, 1997 y 1998).

En todos los resultados mencionados anteriormente el sistema de producción de FVH ha posibilitado obtener mayor calidad de carne; aumento del peso vivo a la fecha de faena; aumento en la proporción de pelo de primera en el vellón de conejos; mayores volúmenes de leche; aumento de la fertilidad; disminución de los costos de producción por sustitución parcial de la ración por FVH (Hidalgo, 1985; Morales, 1987; Pérez, 1987; Bravo, 1988; Valdivia, 1996; Sánchez, 1997; Arano, 1998).

\section{CONCLUSIONES}

El F.V.H. de Zea maíz presenta su pico máximo de contenido proteico en el día decimo a partir del cual empieza a descender levemente hasta el día doce y de allí en adelante presenta un descenso vertiginoso.

El tiempo máximo de germinación de las plántulas no debe exceder el día doce.

\section{REFERENCIAS BIBLIOGRÁFICAS}

1. Cavallaro, S; Rodríguez, G. Ecogénesis, Ambiente y Desarrollo Cultural Derechos de autor protegidos por la ley Argentina 11.723. Disponible en: http://www.ecogenesis.com.ar/index.php?sec=articulo.php\&Codigo=49\#\%5 B1\%5D\#\%5B1\%5D

2. FAO. Alimentación y nutrición. Manual para el control de calidad de los alimentos. 10: Capacitación en análisis de micotoxinas. 144 p. 1991.

3. Garcia, F. J.; Rosello, J.; Santamaria, M. P. Introducción al funcionamiento de las plantas. Editorial Univ. Politec. Valencia. España, 2006.

4. GIANNI DAGLI ORTI/CORBIS. Colección: The Picture Desk Limited Estándar DP Fotógrafo: Gianni Dagli Orti Fecha de creación: $16^{\text {th }}$ Century

5. Hidalgo, Morales, Pérez, Bravo, Valdivia, Sánchez, Arano. Manual técnico forraje verde hidropónico tcp/ecu/066 (a) "mejoramiento de la disponibilidad de alimentos en los centros de desarrollo infantil del innfa" oficina regional de la FAO para América latina y el Caribe. Santiago, Chile, 7 p. 2001.

6. Melo, L.G. Catálogo de Productos. En: Zootek C. A Melo L.G. Catálogo de Productos ZOOTEK C.A. 2007. 
7. Llanos, $\mathrm{P} \mathrm{H}$. Apartes de: La solución nutritiva, nutrientes comerciales, formulas completas. WALCO S.A., Mayo 18 de 2001. En: http://www.walcoagro.com/

8. Oficina Regional de la FAO para América Latina y el Caribe. Roedores como plagas de productos almacenados; control y manejo. Santiago, 2003.

9. Peláez M. J. E. Los grabados de Martin Van Heemskerck: Una visión manierista de las siete maravillas del mundo. Revista Andaluza de arte. [ISSN: 1697-2899 D.L:GR2134/2004] Revista Digital Editada por: Cofradía Nueva del Avellano №11 / 3o Trimestre 3 año. pág. 3. 2006.

10.Pérez-García, F.; Martínez-Laborde., J. B. Introducción a la Fisiología Vegetal. Ediciones Mundi-Prensa. 1994.

11. Rodríguez-Delfín, A.; Tarrillo-Olivas, H. Producción de forraje verde hidropónico como alternativa de alimento para animales de las zonas afectadas por la ola de frío en el Sur del Perú. En: http://www.forrajehidroponico.com/art002.htm

12. Review of international S\&T cooperation projects addressing integrated water resources management Lessons to be learnt. EU Water Initiative Research Component. En: http://www.-ec.europa.eu/research/waterinitiative/images/mexico2006/chinampa fertilising field3.jpg

13. Sauer, D.B.; Burroughs, R. Efficacy of various chemicals as grain mould inhibitors. Trans. Am. Soc. Of Agric Enq, 17: 557-559. 1974.

14. Shimada Miyasaka, Armando. Nutrición animal. Editorial Trillas. p. 27.

15. Salazar Molina, Gustavo. Historia de la hidroponía y de la nutrición vegetal. Disponible

En: http://www.drcalderonlabs.com/Publicaciones/Historia de la Hidroponia/Hi storia de la Hidroponia.htm

16. Universidad Politécnica de Valencia. Germinación de semillas. En: http://www.etsmre.upv.es/varios/biologia/Temas/tema 17.htm 